\title{
Understanding and Modelling the Impact of Climate Change on Infectious Diseases - Progress and Future Challenges
}

\author{
Paul E. Parham ${ }^{1}$, Céline Christiansen-Jucht ${ }^{1}$, \\ Diane Pople ${ }^{1}$ and Edwin Michael ${ }^{2}$ \\ ${ }^{1}$ Imperial College London \\ ${ }^{2}$ University of Notre Dame \\ ${ }^{1} U K$ \\ ${ }^{2}$ USA
}

\section{Introduction}

The effects of global change on human health have attracted increasing attention in recent years, with anthropogenic influences thought to have significant influences on the Earth's climate (Intergovernmental Panel on Climate Change [IPCC], 2007). Climate change is thought likely to have important effects on human, animal and plant life. In addition to indirect effects on human behaviour such as shifting migration patterns, direct effects of climate change on human health are potentially severe. Together with implications through changing air quality, increased exposure to UV radiation, changes in food production, increasing water shortages and contamination, and economic instability, climate change is widely expected to also significantly affect the global spread, intensity and distribution of infectious diseases (Hunter, 2003; McMichael et al., 2006).

In this chapter, we review current knowledge on the impacts of global change on infectious diseases (Section 1), highlighting how combining global and regional climate models with mathematical (and statistical) models of disease transmission (Section 2) provides valuable tools for better understanding future disease scenarios as environmental conditions change. Such models may be used to address important questions on the current and projected impacts of climate change on disease transmission and we illustrate these issues (and the extent to which they have been addressed in modelling work to date) in Section 3. It should be remembered, however, that despite the power of weather, climate and disease models, considerable uncertainties remain. Identifying the origin of these uncertainties, highlighting where improved data may improve model accuracy, realism and confidence, together with translating uncertainties in model inputs into uncertainties in model outputs, are important benefits of modelling. Highlighting where key uncertainties lie is discussed in Section 4, illustrating where future research priorities may be directed to further our understanding of this emerging field. 


\subsection{Key climatic variables}

Although many climatic variables may affect transmission, changes in four main variables are thought to most significantly affect diseases with strong environmental components, namely temperature, precipitation, relative humidity $(\mathrm{RH})$ and wind. Here, we briefly review the impacts of these components on transmission, as well as outlining expected future trends in these variables. It should be noted, however, that climatic variables rarely act in isolation and combinations of variables tend to be associated with climatological niches for optimum transmission of different diseases, e.g. the preferred environmental conditions for optimum proliferation of Anopheles gambiae s.s., An. arabiensis and An. funestus, the three principal vectors of malaria in Africa.

\subsubsection{Temperature}

The cold-blooded nature of most vectors (e.g. mosquitoes, fleas, ticks and flies) results in a strong dependence of disease incidence on ambient temperatures through changes in vector and parasite survival and development (Martens, 1998). Other influences of temperature on vectors include those on biting rates, resting and mating behaviours, dispersal and the duration of gonotrophic cycles (Martens et al. 1995), while effects on humans include changing migration and movement patterns and increasing susceptibility due to immunocompromisation at temperature extremes. The net effect is a non-linear dependence of pathogen vectorial capacity and basic reproduction number on temperature (e.g. Parham \& Michael, 2010).

Global mean surface air temperatures are predicted to increase by several degrees over the next century and while predicted increases over the coming decades are typically consistent between climate models, there is considerable prediction variability from multi-model ensembles over longer timescales for different emissions scenarios and geographic regions. Changes in the occurrence of extreme temperature events are also likely, with predicted increases in more intense, frequent and longer duration episodes (heat waves), along with fewer colder episodes (IPCC, 2007).

Understanding the effect of temperature extremes on disease dynamics has received little attention to date, although strong influences on vectors and parasites at very high and very low temperatures are likely. The survival of malaria-transmitting An. gambiae s.l. mosquitoes, for example, has been shown to sharply decrease at prolonged exposure to temperatures above $40^{\circ} \mathrm{C}$ for immature stages (e.g. Huang et al., 2006) and adults (Kirby \& Lindsay, 2004), particularly at extremes in RH. Variation in predicted temperature changes is significant with latitude, but increases in Africa (with median increases around $3-4^{\circ} \mathrm{C}$ across most of Africa for all seasons) are expected to be greater than the global mean. Predicted increases in regional mean temperatures are likely to cause non-linear changes in disease incidence due to the relationship between temperature and several components of transmission. Process-based models, discussed further in Section 2, however, provide a useful tool for assessing how such complex factors interact and affect prevalence, pathogen reproductive potential and the rate of disease emergence in new regions as climatic conditions change (e.g. Parham \& Michael (2010) in the context of malaria).

\subsubsection{Precipitation}

Precipitation has direct and indirect effects on disease incidence. Direct effects include increased likelihood of water-borne and soil-borne parasitic, bacterial and viral diseases following severe rainfall events, as well as creating new (and modifying existing) breeding 
sites for transmitters of VBDs. Indirect effects include increasing susceptibility through unsafe drinking water, food contamination or enteric diseases.

Rainfall extremes, including floods and storms, will also play an important role. The impact of high rainfall levels and flooding on increasing disease risk is likely to be strongly dependent on country wealth and overall development state, as well as other social and environmental influences. While the population dynamics of vectors will suffer some negative effects of such events (e.g. breeding site destruction from high intensity and volume rainfall increasing immature mortality (e.g. Paaijmans et al. (2007) for malaria)), the net effect is almost always increased vector abundance through breeding site creation. Thus, rainfall has been used as a predictor of VBD incidence for diseases including plague (Parmenter et al., 1999), Rift Valley fever (Linthicum et al., 1999) and malaria (Bi et al., 2003; Thomson et al., 2005). Delays between severe rainfall and vectors identifying new habitats for oviposition, plus other effects such as delays in water temperature reaching suitable levels for immature survival, often result in lags between rainfall events and sharp increases in disease prevalence (Briet et al., 2008; Kristan et al., 2008).

Drought and desiccation are also thought to play important roles. As well as indirect effects such as increasing human susceptibility due to changing immune status from water and food scarcity, the absence of water and soil moisture for prolonged periods decreases vector abundance due to the absence of suitable breeding sites.

Global mean precipitation is predicted to increase under future climatic conditions, together with increases in the intensity (but decreases in the frequency) of extreme rainfall events. Increases in precipitation appear almost independent of the emissions scenario over the coming decades, but display considerable variability thereafter (IPCC, 2007). Indeed, changes in rainfall patterns may have more influence on health risks from climate change than global warming (Allen \& Ingram, 2002). However, in contrast to temperature trends, variability in rainfall predictions between models is considerably greater, particularly at lower latitudes. Increases in the intensity of rainfall extremes are projected to be even greater than increases in mean precipitation changes, with associated increased disease risks from flooding and droughts. Despite projected regional changes in seasonal and decadal rainfall patterns differing between climate models, ensemble model predictions highlight significant spatial heterogeneity in expected precipitation pattern changes. Decreasing seasonal rainfall across South African regions, for example, contrasts markedly with projected increases across East Africa (IPCC, 2007).

Despite uncertainty and variability in global rainfall predictions across different models, rainfall increases in East Africa, particularly during the winter months, show greatest robustness in predictions of all African regions. Together with associated temperature increases of around $3^{\circ} \mathrm{C}$ for all seasons, this has attracted increasing attention in the context of malaria dynamics, with research focussing on questions such as whether recent prevalence changes indicate that climate change effects are already underway in this region (Hay et al. 2002a, 2002b, 2005; Pascual et al., 2006, 2008; Zhou et al., 2004).

\subsubsection{Relative Humidity (RH)}

Changes in RH are most likely to affect the dynamics of VBDs and while effects on parasite development within vectors are unlikely (although uncertain), considerable influences on human health and vector population dynamics (and behaviour) are evident. Extremes in $\mathrm{RH}$ have been shown to adversely affect human health (Baughman \& Arens, 1996), worsening chronic diseases such as asthma (and other lung and respiratory diseases) and potentially 
increasing susceptibility to infectious diseases. The effects of changes in $\mathrm{RH}$, however, are likely to most significantly affect vectors, notably on adult survival and activity.

For An. gambiae s.l. mosquitoes transmitting malaria, mean adult survival is considerably shortened below 50-60\% RH and reduced (albeit by a smaller amount) close to $100 \%$ (Pampana, 1969; Warrell \& Gilles, 2002), suggesting an optimum RH range for survival. Increased RH has also been shown to affect An. gambiae s.l. reproduction, increasing vector abundance (Jawara et al., 2008). However, the favourability of individual species within the An. gambiae complex to RH conditions may vary substantially (Colluzi et al., 1979) and changing patterns of land use have been shown to affect $\mathrm{RH}$, e.g. deforestation has been associated with increased vector abundance (Afrane et al., 2007).

Globally averaged $\mathrm{RH}$ is thought to remain approximately constant under climate change and this appears to be a feature of current general circulation models (GCMs) (Allen \& Ingram, 2002). Recent work on creating and analysing the first global humidity dataset has shown that $\mathrm{RH}$ is almost constant on large spatiotemporal scales, but considerable regional structure and temporal variability remains (e.g. diurnal RH variability may be around $25 \%$ ) (Willett et al., 2008). Global trends over land are typically negative, but not significant (Willett et al., 2008), and conditions of constant RH serve as further evidence of global warming (Willett et al., 2007). Comparisons between recent RH land means and global maps of malaria prevalence (e.g. Hay et al., 2009) are consistent with the notion of optimum RH for high prevalence, although given the lower density of weather stations contributing to the humidity dataset in the tropics (Willett et al., 2008), further research is required to better understand $\mathrm{RH}$ trends and anomalies in areas most severely affected by malaria.

\subsubsection{Wind}

Global and local changes in wind patterns have three principle effects on infectious diseases, namely (a) affecting the dispersal ability and behaviour of disease vectors (or direct wind-borne pathogen spread), (b) changing hydrological processes such as evaporation that affect vector abundance and (c) affecting human susceptibility due to extreme weather events such as storms and tropical cyclones. Little research has examined the potential impact of changes in wind patterns on diseases, although some work has examined the effect on animal diseases (e.g. Kedmi et al. (2010) on epizootic hemorrhagic disease virus in dairy cattle and Sellers et al. (1985) on bluetongue in sheep). Peak wind and near-storm precipitation intensities are predicted to increase in future tropical cyclones (IPCC, 2007).

\subsection{Current knowledge on the potential impact of climate change}

We focus here on providing an overview of the main infectious diseases thought to be strongly affected by climate change, primarily focusing on VBDs, although we also consider the potential impacts on water-borne and other diseases. We focus solely on human diseases, but note that the effects of climate change have also been considered on nonhuman diseases such as bluetongue, Eastern and Western equine encephalitis, Western Venezuelan equine encephalitis and African horse sickness (Githeko et al., 2000; Summers, 2009). In the case of bluetongue, for example, incidence has been shown to increase most where temperature increases have been greatest and where minimum climatic conditions are met for transmission (Purse et al., 2005). 


\subsubsection{VBDs}

The sensitive nature of arthropod species to changes in climatic variables suggests that of all the infectious diseases potentially susceptible to climate change, VBDs are the most sensitive and we may see shifts in VBD distribution over the coming decades and centuries (WHO, 1999). While there is much speculation on future incidence trends with climate change, few empirical studies have emerged to determine whether impacts are already underway and considerable debate has arisen from those that have (McMichael et al., 2006). This is nowhere better illustrated than the recent (and ongoing) debate about the relationship between malaria and meteorological trends in the East African highlands (Hay et al. 2002a, 2002b, 2005; Pascual et al., 2006, 2008; Zhou et al., 2004).

The link between vector survival and lifecycle processes and climatic variables indicates only that VBDs can be affected by climate change; the magnitude and extent of the change given the many factors affecting incidence is perhaps the most important question for the field. The global distribution of malaria, for example, is thought to almost certainly change with climate (e.g. Cook, 1992; Sutherst, 2004), although the magnitude of this change may be relatively small (Rogers \& Randolph, 2000), yet VBD transmission is dependent on a multitude of epidemiological, environmental, social, economic and demographic factors (Martens et al., 1995; McMichael et al., 2006). Indeed, mitigating climate change may result in only a very small reduction in the population at risk of malaria by 2080 (Goklany, 2004). Local infrastructure and wealth may also influence the risk of disease emergence in new regions (and the treatment of individuals should outbreaks arise), although the risk of imported infections should not be dismissed (Hunter, 2003; Isaacson, 1989).

Temperature, rainfall and $\mathrm{RH}$ thresholds critically affect the geographic regions conducive to malaria transmission, with the majority of cases contained within latitudes of $30^{\circ} \mathrm{N}$ to $30^{\circ} \mathrm{S}$ (Hales \& Woodward, 2005; Hay et al., 2009), although the possibility of European outbreaks has also been considered (WHO, 1999). However, within regions where climatic sufficiency conditions exist for transmission (and where rainfall sufficiency is usually thought to be more crucial than temperature (e.g. Mabaso et al., 2006)), considerable research is required into the role of climatic influences compared to other factors driving disease dynamics. These include land use changes (including deforestation), changes in transportation infrastructure, changes in immunity, drug and insecticide resistance, urbanisation and the impact of control measures (Afrane et al., 2007; Hay et al., 2002; Lindblade et al., 2000). Local landscape also plays an important role (Ernst et al., 2006) and altitudinal effects on incidence have been considered (Lindsay \& Martens, 1998; Reiter, 2008), along with changes in human behaviour (Martens \& Hall, 2000; Tatem et al., 2006). In addition, rainfall has been shown to significantly affect vector population dynamics, increasing the number of suitable larval breeding sites, adult abundance, biting rates and the duration of gonotrophic cycles, as well as the seasonal dynamics of different Plasmodium strains (Koenraadt et al., 2004; Molineaux et al., 1980; Ndiaye et al., 2006).

Severe climatic events such as ENSO may have disproportionately large effects on disease trends (Kovats et al., 2003), with sudden increases in temperature, rainfall and RH shown to have caused sharp increases in malaria incidence in Punjab and Sri Lanka (Githeko et al., 2000) and Columbia (Bouma et al., 1997; Mantilla et al., 2009). Such climatic anomalies have been used to drive seasonal malaria forecasts (Thomson et al., 2005, 2006). Changes on shorter timescales (e.g. diurnal cycles) have been shown to have important implications for transmission (Paaijmans et al., 2010), since non-linear relationships between temperature 
and components of transmission mean that small changes in the former may have large effects on the latter, particularly in the most vulnerable regions (Sutherst, 2004).

Alongside malaria, dengue and schistosomiasis are also thought to be significantly affected by climatic changes (Martens, 1998), yet these diseases combined represent less than $7 \%$ of the global mortality due to malaria (WHO, 2008), which has therefore attracted most attention to date. However, despite the low mortality rate, the global burden of dengue remains high and it is thought to annually infect around 50-100 million people worldwide, remaining endemic in more than 100 countries (Whitehorn \& Farrar, 2010). Dengue transmission demonstrates a similar global distribution to malaria, being primarily concentrated in the tropics and subtropics (Hopp \& Foley, 2003; López-Vélez \& Moreno, 2005), although this is likely to be affected by climate change (Cook, 1992) and shifts in altitudinal range are also possible (Chan et al., 1999). Transmission occurs via Aedes mosquitoes, primarily Aedes aegypti, although the introduction of Aedes albopictus into Europe over the last 15 years has raised the threat of dengue re-introduction into Europe (Semenza \& Menne, 2009), as well as the possibility of the re-emergence of other VBDs such as chikungunya (Hochedez et al., 2006).

Aedes abundance has been shown to positively correlate with rainfall and humidity (Gubler et al., 2001; Watts et al., 1987), increasing mean temperatures and the occurrence of ENSO events (Gagnon et al., 2001; Hales et al., 1999; Herrera-Martinez \& Rodríguez-Morales, 2010), with changes in humidity potentially playing a significant role (Hales et al., 2002). The development rate of the dengue virus within Aedes is strongly influenced by ambient temperature (Martens, 1998; WHO, 1999), e.g. reducing from an incubation period of 12 days at $30^{\circ} \mathrm{C}$ to 7 days around $32-35^{\circ} \mathrm{C}$ (López-Vélez \& Moreno, 2005).

Climatic changes are also likely to affect the global distribution of schistosomiasis (Cook, 1992; Martens, 1998; Mas-Coma et al., 2009), with transmission potential thought to be particularly sensitive to climate change around the edges of current endemic areas (Sutherst, 2004). Indeed, decreases in snail abundance due to increased mortality with global warming may reduce the epidemic potential of schistosomiasis in these regions (Epstein, 2001), although other areas (e.g. China) may experience an increase in areas suitable for transmission (Yang et al., 2005). Importation of cases into areas previously endemic is also a concern in several areas (e.g. Casimiro et al., 2006).

Other VBDs have also attracted recent attention in the context of climate change. The effects of global warming may cause shifts in the geographic distribution of vectors (through changing migration patterns) and changes to the duration of transmission seasons, with implications for diseases such as tick-borne encephalitis (TBE) and Lyme disease (Epstein, 2001; WHO, 1999). Increasing incidence of the latter has been found in several European countries (Semenza \& Menne, 2009), with re-emergence under climate change also considered (Casimiro et al., 2006).

For TBE, milder winters and drier summers are thought to decrease and increase tick activity respectively (Githeko et al., 2000), with implications for tick abundance at higher altitudes and latitudes (Gray et al., 2009). Indeed, given that several parameters appearing in an expression for the basic reproduction number $R_{0}$ (see Section 3.1) of tick-borne diseases depend on climatic variables (Randolph, 1998), such diseases are likely to be sensitive to future environmental changes, particularly changes in temperature and RH (Randolph, 2004; Suss et al., 2008), e.g. Rocky Mountain spotted fever (Gubler et al., 2001).

Mosquito-borne diseases, more generally, are likely to experience important changes in transmission potential given the sensitivity of vector and pathogen survival, development 
and replication to changes in mean climatic drivers and temporal fluctuations about the means (Khasnis \& Nettleman, 2005; Reiter, 2001), although factors such as changes in population growth or density may also play a strong role (Tol \& Dowlatabadi, 2001). Through changes in vector abundance, distribution and seasonal activity, climatic changes may affect the incidence of other diseases such as leishmaniasis, Yellow Fever, Japanese encephalitis, arboviral diseases, African trypanosomiasis, lymphatic filariasis, onchocerciasis and dracunculiasis (Cook, 1992; Githeko et al., 2000; Gubler et al., 2001; Michael, 2009; Reiter, 2001; Sutherst, 2004). Changes in the patterns of Ross River virus, West Nile virus, Rift Valley fever, American trypanosomiasis and St. Louis encephalitis with climatic variables have also been reported (Epstein, 2001; Casimiro et al., 2006; Gubler et al., 2001; Michael, 2009; Semenza \& Menne, 2009).

\subsubsection{Other infectious diseases}

Around $23 \%$ of global deaths due to infectious and parasitic diseases are due to diarrhoeal diseases, with almost half of these occurring in Africa (WHO, 2008). Higher temperatures are shown to frequently accompany increased incidence (McMichael et al., 2006); developing countries, for example, are predicted to show a $5 \%$ increase in incidence per $1{ }^{\circ} \mathrm{C}$ temperature increase (Campbell-Lendrum et al., 2003). Changing environmental conditions may therefore strongly affect the intensity and distribution of water-borne diseases through changes in water quality and availability (Hunter, 2003), e.g. sharp increases in leptospirosis after strong rainfall events and flooding (Githeko et al., 2000; Gubler et al., 2001).

Temperature changes are known to affect the population dynamics of phytoplankton and zooplankton, which in turn affect the abundance of bacteria causing cholera (Lipp et al., 2002), the geographic range and dynamics of which may alter with climate change (Koelle et al., 2005; Pascual et al., 2002). The correlation between ENSO events and cholera has also been considered (e.g. Pascual et al., 2000).

Other impacts include those on food-borne diseases due to higher temperatures increasing bacterial survival and proliferation (Hall et al., 2002). Indeed, correlations have been observed between short-term increases in temperature and both food poisoning (McMichael et al., 2006) and increases in diseases such as salmonellosis and botulism (Semenza \& Menne, 2009; WHO, 1999). The link between climatic variables and the incidence of rodent-borne diseases has been reported for diseases such as plague (Githeko et al., 2000; Gubler et al., 2001), as well as influences on soil-borne diseases such as melioidosis (Inglis \& Sousa, 2009).

\section{The use of models to understand disease transmission}

The first application of mathematical modelling to infectious diseases is often attributed to work on smallpox eradication by Daniel Bernoulli in the 18 th century (Bernoulli 1760), yet many of the methods currently applied to address public health questions have been developed over the last few decades (e.g. Anderson \& May, 1991; Daley \& Gani, 1999; Keeling and Rohani, 2007), and application of these methods to model specific pathogens or outbreaks have increased considerably since the mid-1980s.

\subsection{Types of disease modelling framework}

A range of mathematical frameworks are applicable for the development of environmentally-driven disease models and these may be categorised as taking one characteristic from each of the following classifications. 


\subsubsection{Population and Individual-Based Models (IBMs)}

The primary population models for describing infectious disease transmission are typically compartmental in nature, aggregating individuals according to their disease status and tracking how the number of individuals in each class changes over time. In IBMs, each member of the population is modelled, taking into account individual characteristics or risk factors, and tracking the influence of demographic, social, climatic, environmental or epidemiological processes over time. Population models may take any of the mathematical forms below, while IBMs are typically stochastic as individuals undergo epidemiological processes with a certain probability. The introduction of $p$-state and $i$-state variables by Metz and Diekmann (1986) provides a formal means of distinguishing between population models and IBMs.

\subsubsection{Continuous and discrete-state models}

Models of the former type are described by continuous $i$-state or $p$-state variables, so that state variables may take infinitely many values within an interval. In the latter case, state variables may take only a finite number of values (e.g. matrix population models or models where only an integer number of individuals is permitted).

\subsubsection{Deterministic and stochastic models}

In deterministic models, specifying parameter values, the initial values of state variables and a set of equations describing how initial states evolve over time results in model outputs that do not change from one simulation to the next. Mathematical descriptions of deterministic models are generally ordinary differential equations (ODEs), delaydifferential equations (DDEs), partial differential equations (PDEs) or integro-PDEs (in continuous-time) or difference equations (in discrete-time). Stochastic models are formulated in terms of random variables, so that even for a fixed set of initial conditions, parameters and rules for evolving state variables, repeated runs of the same model produce different outputs. Stochastic effects are important when population sizes become small and may be used to capture uncertainty, variability and/or noise in disease or climate processes.

\subsubsection{Continuous and discrete-time models}

In the former, time evolves smoothly over an interval, so that model parameters reflect the rate at which events occur, and such models are often described by a set of differential equations. In the latter, the values of state variables are tracked only at certain time points, typically of fixed separation, and such models are usually described by difference, delaydifference or integro-difference equations.

\subsubsection{Non-spatial and spatial models}

Non-spatial models assume spatially homogeneous and isotropic transmission, so that each individual is assumed to be infected by all other members of the population with equal likelihood, irrespective of the distance between them. Most pathogens, however, have a spatially local component to transmission, where this spatial element may be in geographic space (i.e. Euclidean distance) or social space (e.g. in terms of human contact networks). Spatial models may be further classified as continuous or discrete-space models and reviews of spatial modelling (and model types) have appeared elsewhere (e.g. Keeling, 1999). 


\subsubsection{Homogeneous and heterogeneous mixing models}

Models assuming homogeneous mixing assume no preferential contact between any two individuals in the population, so that if all individuals have the same contact rate and infection is passed on with a fixed probability per contact, then the model assumes a fixed force of infection across all contact pairs. For pathogen transmission where transmission risk is heterogeneous and varies across pairs of susceptible and infectious individuals according to $i$-state characteristics of the individuals involved, mixing patterns may be described by WAIFW (Who Acquires Infection From Whom) matrices, where homogeneous mixing occurs as a special case when all elements of the matrix are equal.

\subsubsection{Models embedded within static or dynamically-varying environments}

Here, the environment refers to all processes or influences on disease dynamics external to an individual and these include mixing patterns, contact structure, population demographics, drug resistance, intervention measures and climatic conditions. Disease dynamics of models assuming static environments arise solely from the interaction between intrinsic model processes, while in models whose environments change over time, both intrinsic and external processes may drive dynamics. Mathematically, the latter class of models are frequently implemented through temporal changes in model parameters and this occurs in climate-driven models through, for example, daily temperature variability affecting processes such as vector survival or parasite development.

Given this variation in available approaches, the choice of disease modelling framework to better understand the effects of climate change depends on a range of factors, primarily data availability and the questions of interest. Certain model types will prove advantageous over others when investigating the effect of environmental variables depending on the issues under consideration, the timescale available for the investigation, knowledge on disease natural history, the degree of analytical versus numerical insight required into spatiotemporal dynamics as climatic conditions change, and data availability for model calibration and validation. Other considerations may include computational resources (e.g. IBMs and climate models are very computationally intensive) and known uncertainties (or variability) in disease and climate inputs.

\subsection{The role of modelling}

In the context of understanding how global change will affect infectious diseases, both statistical and mathematical models have important roles to play. Statistical models use descriptive correlations between explanatory and response variables (here, climate and disease respectively) to predict the future state of systems based on past behaviour. Such models offer no explanations as to underpinning biological mechanisms driving predicted changes, although inferences are normally derived from the results obtained (see Section 3.2). Mathematical models, on the other hand, adopt a process-based approach, combining known biological, epidemiological and/or environmental processes to formulate assumptions that characterise the model. Future states of the system are predicted given the initial state and by comparing model output with observations on incidence, mathematical models offer explanatory power. We focus here on the role of dynamic mathematical models.

Models provide a useful bridge between individual-scale processes, behaviour and environmental conditions and population-level observations on disease spread. As such, 
key principles underlying relationships between climate and disease may be elucidated, interactions between components affecting transmission may be better understood and patterns of prevalence may be explainable in terms of underlying processes. Model calibration and validation may provide a means of reliably predicting short and long-term disease dynamics, both under the assumption of unchanging model processes and where extrapolation of current observations to future scenarios is required when factors driving transmission change. Such models offer a major advantage over statistical models in this respect, which rely on the relationship between response and explanatory variables remaining constant. Extrapolation is based on current background conditions and the strength of existing associations between explanatory and response variables, an assumption that is questionable over the timescales characteristic of climate change.

Mathematical models also allow us to better understand the dynamics of complex systems involving interactions and feedbacks between multiple non-linear processes. Climate models are frequently associated with extreme sensitivity to initial conditions, while chaotic behaviour has also been observed in disease models (e.g. Bolker \& Grenfell, 1993), and models may be used to overcome difficulties in our intuition at understanding the behaviour of systems with complex, non-linear and chaotic phenomena. This is particularly relevant to climate-driven infectious disease systems because of the complex behaviour that external drivers of dynamics, which climate variables embody, can introduce into disease transmission such as cyclical or chaotic dynamics (see below). Well-validated models may be used for short and long-term prediction, testing hypotheses and potentially acting as early warning systems for disease outbreaks in response to climatic phenomena (e.g. ENSO). They may also provide the basis of sensitivity analyses, enabling a better understanding of the response of disease dynamics to changes in model parameters, either epidemiological or climatic, as well as enabling identification of areas where improved data is required.

Perhaps most importantly, mathematical models may be used in scenario analysis to better understand (a) the impact of climate change mitigation on transmission, (b) how the interaction between climate and vector-borne, water-borne and other infectious diseases may influence climate change adaptations and (c) the influence of climatic variables and other drivers of disease on intervention dynamics. Such analysis may be used in long-term planning of disease control programmes, as well as utilising models as a means of quantifying uncertainties in disease and climate knowledge (see Section 4) and how this translates into uncertainties in the effectiveness of proposed intervention strategies.

\section{Disease models in the context of climate change: The need to incorporate complexity}

\subsection{Large-scale effects of climate on disease transmission}

Climatic variables affect processes associated with transmission in numerous ways and these may be broadly categorised as:

a. Direct effects on physical and physiological processes (e.g. changes in vector survival and the rate of blood meal processing with changing temperatures).

b. Indirect or intermediate effects on physical processes (e.g. hydrological processes affecting the creation and modification of vectors breeding sites through changing rainfall patterns). 
c. Changes in human geography (e.g. land use changes such as deforestation, urbanisation or migration affecting the distribution of regions susceptible to emerging outbreaks).

d. Changes in the intensity, frequency or geographic distribution of extreme weather events such as droughts, flooding, heat waves and cold waves.

e. Changes in human susceptibility to diseases through immunosuppression due to factors such as changes in chronic cardiorespiratory diseases, malnutrition or water shortages.

f. Changes in intermediate host population dynamics (e.g. regional changes in vector abundance or bacterial proliferation causing increased water-borne or food-borne diseases).

Such effects raise important questions that realistic models, both mathematical and statistical, should address and both types of models, when used in combination, may provide powerful causative and descriptive links between climate and disease changes. As well as changes in the mean values of climatic variables, temporal variability is also likely to play a significant role (e.g. Zhou et al., 2004), so assessing the effects of climate variability (and uncertainty) on transmission is vital. Temporal variability in disease models may arise from a number of sources (Grassly \& Fraser, 2006), the basic mechanisms for which, in this context, arise from (a) changing contact patterns or behaviour over time (e.g. human behaviour in response to severe weather events or changing vector dispersal patterns), (b) temporal variability in environmental variables driving microscale processes (e.g. diurnal temperature fluctuations or longer-term land use changes), (c) fluctuations in intermediate host population dynamics (e.g. tick or snail abundance in response to changing environmental variables) or (d) changes in host immunity (Parham \& Michael, 2011).

Models may also be used to address questions such as the appearance of disease thresholds in the context of system resilience and stability (Gambhir \& Michael, 2008; Scheffer et al., 2001), assessing the impact of climate mitigation and disease intervention measures, integrating economic considerations to assess the scale, nature and timing of control strategies given limited resources, and better understanding dynamic interactions between diseases. More specific epidemiological concepts may also be investigated such as the effects of climatic drivers on the basic reproduction number $R_{0}$ (defined as the average number of secondary infections generated per primary case (Anderson \& May, 1991)), invasion properties (such as the probability of establishment (or fade-out) of outbreaks in newly vulnerable regions), the rate at which incidence increases and longterm disease persistence.

\subsection{Examples of models to date}

\subsubsection{Statistical and semi-mechanistic-based approaches}

Research to date developing integrated malaria models has included both statistical and biological (process-based) approaches. An early statistical model used fuzzy logic to quantify the suitability of different regions within sub-Saharan Africa for transmission given local temperature and rainfall conditions (Craig et al., 1999), while Rogers \& Randolph (2000) used a statistical approach to show that that the global malaria distribution may not change considerably by 2050. Other work has used spatial models and risk maps to demonstrate that changing population densities may be a crucial factor determining future malaria risk in Africa (e.g. Moffett et al., 2007), while the impact of climatic drivers versus developmental variables (such as local infrastructure, income and land use changes) has been considered in India (Garg et al., 2009). A semi-mechanistic modelling approach has also 
been used to analyse the role of rainfall in driving long-term malaria dynamics in the highlands of Kenya (Pascual et al., 2008).

\subsubsection{Mechanistic modelling approaches}

The first mechanistic modelling to introduce climatic variables into integrated disease frameworks (and consider associated health impacts) was developed in the late 1990s (Lindsay \& Birley, 1996; Lindsay \& Martens, 1998; Martens, 1998; Martens et al., 1995). Changes to the regions at risk of malaria, dengue or schistosomiasis under different emissions scenarios were assessed using the concept of epidemic potential (EP), defined as the inverse of the critical number of vectors per human required to ensure $R_{0} \geq 1$, so that low $\mathrm{EP}$ indicates the need for either high vector numbers or low human densities (or both) for infection to establish and become endemic. The expression for EP arises from an underlying deterministic non-spatial ODE model at equilibrium and thus assesses infection risk using the statics properties of disease transmission. Vector and human population dynamics, as well as disease dynamics, are assumed to be at equilibrium and no dynamical influences on disease risk are assumed.

As well as illustrating the insufficiency of vector abundance and climatic conditions as sole indicators of disease transmission potential (since factors such as the impact of control measures and the characteristics of local human or vector populations should also be considered), this work illustrates the highest risk of disease invasion to regions bordering current endemic areas, as well as populations at higher altitudes (Martens et al., 1995), although this risk is sensitive to local temperature and rainfall conditions under different emissions scenarios (Lindsay \& Martens, 1998). This research is generalised by Janssen \& Martens (1997) to consider the role of evolutionary insecticide and antimalarial drug resistance on the effectiveness of intervention measures. Areas of low endemnicity may suffer less severe consequences of resistance (incidence typically reduces with control measures) compared to regions with high endemic malaria, which may suffer increased incidence as a result of resistance, although the contrast between these cases depends on the climate change scenario. Results are based on a dynamic ODE transmission model for a human population at quasi-equilibrium (but assuming an equilibrium vector population). Frameworks developed in the early modelling literature are combined with comparable qualitative studies and generalised into an integrated assessment framework for understanding the effects of climate change on diseases in Chan et al. (1999), identifying the need to assess possible impacts due to ecological, biological and socio-economic factors.

While early modelling work on malaria, dengue and schistosomiasis make valuable contributions to the field, considerable limitations are apparent. Most notable of these are (a) consideration of only static aspects of disease transmission (and human and vector population dynamics) to assess infection risk, (b) limited or poor parameterisation of interactions between hosts, vectors and pathogens in terms of climatic (and other environmental) variables and (c) limited development of realistic disease transmission models beyond low-dimensional ODE approaches. To overcome the assumption of equilibrium vector populations, Shaman et al. (2002) develop a detailed dynamic simulation model, coupled to land surface hydrology, to model the abundance of Anopheles, Aedes and Culex mosquitoes, while Ahumada et al. (2004) use the concept of physiological age to develop a matrix population model of Culex quinquefasciatus dynamics under daily fluctuations in ambient temperature and rainfall conditions. 
Of relevance to malaria is the discrete-time stochastic IBM of Depinay et al. (2004) who consider the effects of abiotic (temperature and moisture) and biotic (nutrient competition, predation and dispersal) factors on Anopheles ecology to predict adult abundance time series given daily variability in microclimates. Few other dynamic vector population models linked to climate have been developed to date, although those of note include the matrix model of Aedes dynamics by Schaeffer et al. (2008) and the fully-coupled hydrology and entomology model of Bomblies et al. (2009), which also links simulated vector abundance with local malaria risk.

Integrating better-parameterised and more realistic dynamical population and transmission models represents the current state of the art, although considerable difficulties and uncertainties remain (see Section 4). Arguably the most recent and comprehensive research in this respect is that of Hoshen \& Morse (2004) (and Hoshen \& Morse (2005)), recently updated and improved in terms of model parameterisation, calibration and validation (Ermert et al., 2011a, 2011b), who use a discrete-time model (based on physiological age) to better understand the link between vector dynamics and malaria transmission under different environmental conditions. Such models may be used for better understanding static and dynamic aspects of transmission under future climate scenarios, particularly when combined with mapping work elsewhere (e.g. Hay et al. (2009)), and the use of multimodel ensembles to improve model confidence (Hoshen \& Morse, 2004) represents an approach that has already been integrated in climate modelling (see Section 4). Few other integrated dynamical studies currently exist (although see the entomological model linked to climate in Ruiz et al. (2006)), but work focussing on static aspects of transmission have also made valuable recent contributions. These include the effect of diurnal temperature cycles on malaria risk under different mean climatic conditions (Paaijmans et al., 2010), the role of the Normalised Difference Vegetation Index (NDVI) in driving seasonal transmission (Gaudart et al., 2009) and the influence of temperature on malaria invasion under different climatic regimes (Parham \& Michael, 2010).

Fewer modelling studies on the influence of climate change on other VBDs have been carried out to date, although this represents an emerging modelling field. However, some work has been carried out to date on the impact on schistosomiasis and dengue (e.g. Cross \& Hyams, 1996; Hales et al., 2002; Yang et al., 2010), representing the two most likely VBDs to be affected by climate change behind malaria (Martens, 1998; McMichael et al., 1996). Other modelling studies have included those on Lyme disease (Brownstein et al., 2005) and TBE (Randolph \& Rogers, 2000).

\section{Conclusion}

Despite considerable progress in the last decade in our understanding of the link between climate change and the consequences for human infectious diseases (and other health risks) (McMichael et al., 2006), considerable work remains, particularly in better understanding the role of environmental drivers versus other epidemiological factors known to drive transmission. Current uncertainties may be categorised as those related solely to epidemiological aspects independent of climate, those related to uncertainties associated with climate models themselves and those related to the interaction between disease and climate. Understanding, quantifying and improving our knowledge in each of these areas is vital if we are to better understand the challenges that lie ahead.

Understanding vector population dynamics represents an important area requiring considerable further research. For Anopheles mosquitoes transmitting malaria, for example, a 
major cause of mortality in immature stages is thought to be predation and other densitydependent effects (Juliano, 2007; Mogi et al., 1984; Service, 1977), while similar effects have been reported in Aedes (Dye, 1984) and Culex (Lundkvist et al., 2003) mosquitoes. Data availability (and quality) with which to parameterise density-dependence in population models, however, is currently sparse, partially due to the difficulty in undertaking experiments replicating realistic field environments (Service, 1993) and partially due to the qualitative nature of many field observations (e.g. on predator-prey interactions).

Intra-species and inter-species competition is often observed between vectors (Kirby \& Lindsay, 2009; Paaijmans et al., 2009), with associated impacts on predators' species preference in the presence of multiple prey (Bradshaw \& Holzapfel, 1983). The limited quantitative data available on Anopheles rarely distinguishes between the behaviour of species within the An. gambiae complex and An. funestus (or indeed clarifying stage-specific immature behaviour). Indeed, taxonomy issues often complicate parameterisation of vector population models using historical data (Lane \& Crosskey, 1993; Mattingly, 1977). More recent experiments on vector species can also introduce taxonomic uncertainty owing to time or resource constraints (e.g. Fillinger et al., 2004).

Thus, detecting, measuring and modelling density-dependent effects is extremely challenging (e.g. Hassell, 1987; Solow \& Steele, 1990), even if species-specific data is available, and understanding such effects in adult vectors is even more difficult, with few studies to date (e.g. Charlwood et al. (1995) for the limited research to date on effects in adult Anopheles). Given the strong influence of such biotic effects on vector abundance, and hence VBD transmission, this represents a major source of uncertainty, particularly since such effects may not even be consistent across all habitats for the same species (Juliano, 2007).

In addition to biotic uncertainties with vector (and bacterial) population dynamics, understanding the influence of abiotic effects, such as those from climatic and other environmental variables, is key. In the case of VBDs, environmental factors are likely to affect each component of the disease triangle of hosts, vectors and pathogens, although the magnitude (and timescale) of the effects on each remain uncertain. Reliable parameterisation of the effects of temperature, rainfall, $\mathrm{RH}$, wind patterns and other climatic variables on the range of possible disease vectors requires further experimental studies (e.g. Depinay et al., 2004; Ermert et al., 2011a, 2011b). Research to date has shown that these interactions may have important non-linear influences on vector and pathogen dynamics, which will strongly affect disease dynamics when incorporated within realistic disease transmission models.

Improved parameterisation of microscale interactions between climatic and epidemiological processes affecting the disease triangle thus represents a major source of uncertainty in current climate-driven disease models, although these have served to highlight where improved data is required. In addition, little research has considered the interaction between biotic and abiotic factors affecting transmission, but predation and other densitydependent effects, for example, may depend on climatic and other environmental variables (e.g. Sunahara \& Mogi, 2002). Temperature effects on mosquito mortality, development and activity may affect the population dynamics of species in upper and lower trophic levels, changing the nature of predator-prey interactions (Service, 1977).

Considerable heterogeneities also exist across the disease triangle and these include variability in the nature of climate and disease relationships for VBDs, for example, by vector species (e.g. variability within the An. gambiae complex and between other Anopheles species) and parasite strain (e.g. different temperature responses of the malaria parasites Plasmodium falciparum and $P$. vivax). Understanding heterogeneity in risk factors for human 
susceptibility to diseases affected by climate change is also important and the presence of non-communicable diseases (e.g. cardiorespiratory disorders) may contribute to increased risk of infectious diseases in vulnerable populations, as well as changes in human behaviour, movement and land use. Other epidemiological uncertainties (independent of environmental factors) also remain (e.g. immunological responses, issues of cross-immunity and multiple infections), as well as the need to integrate epidemiological and environmental factors into frameworks incorporating socio-economic considerations, social factors and the impact of intervention measures to assess current and future disease risks.

As well as improving our understanding of the interactions between population, disease and environmental processes (and uncertainties therein), understanding the impact of climate change on infectious diseases also requires knowledge of the uncertainties in climate modelling. Uncertainties surrounding the development, reliability and performance of GCMs, downscaling to regional climate models (RCMs) and the use of climate model ensembles have been considered elsewhere (e.g. Knutti, 2008; Murphy et al., 2004; Slingo et al., 2009). Types of from uncertainties include structural (e.g. arising from the type of climate model used), process-based (e.g. assumptions regarding sub-grid and neglected processes), parameterisation issues (e.g. regional variability in model parameters), choice of initial conditions (and boundary conditions for RCMs) and variability between emissions scenarios, together with issues such as the choice and stability of numerical algorithms used to solve model equations.

Quantifying uncertainties in climate model predictions is vital if we are to translate these into the implications for global and regional disease risk using transmission models, themselves possessing uncertainties. Understanding the sensitivity of disease models to uncertainties in model inputs and how these propagate into uncertainties in model predictions represents an important area. Understanding the limitations of current climatedriven disease models given climatological unknowns (and limitations in computational power) is important if we are to improve the reliability of future models and the robustness of predictions under climate change. The use of multi-model ensembles in climate modelling has already become an established technique (e.g. Palmer et al., 2005; Tebaldi \& Knutti, 2007) and although some disease modelling has incorporated ensemble climate model predictions (e.g. Morse et al., 2004, 2005), ultimately we may require full integration of multi-model ensembles of climate and disease models to improve our understanding of future changes in disease spread and the implications for mitigation, adaptation and control.

\section{Acknowledgements}

Paul E. Parham would like to thank the Grantham Institute for Climate Change at Imperial College London for funding this research.

\section{References}

Afrane, Y. A., Zhou, G., Lawson, B. W., Githeko, A. K. \& Yan, G. (2007). Life-table analysis of Anopheles arabiensis in western Kenya highlands: effects of land covers on larval and adult survivorship. American Journal of Tropical Medicine and Hygiene, Vol. 77, No. 4, (October 2007), pp. 660-666, ISSN 0002-9637

Ahumada, J.A., Lapointe, D. \& Samuel, M.D. (2004). Modeling the Population Dynamics of Culex quinquefasciatus (Diptera: Culicidae), along an Elevational Gradient in 
Hawaii. Journal of Medical Entomology, Vol. 41, No. 6, (November 2004), pp. 11571170, ISSN 0022-2585

Allen, M. \& Ingram, W. (2002). Constraints on future changes in climate and the hydrologic cycle. Nature, Vol. 419, No. 6903, (September 2002), pp. 224-232, ISSN 0028-0836

Baughman, A. \& Arens, E. (1996). Indoor humidity and human health .1. Literature review of health effects of humidity-influenced indoor pollutants, Proceedings of 1996 Winter Meeting of the American Society of Heating Refrigerating and Air Conditioning Engineers. Atlanta, GA, February 1996

Bernoulli, D. (1760). Essai d'une nouvelle analyse de la mortalité causée par la petite vérole et des advantages de l'inoculation pour la prevenir. Memoirs of the Royal Mathematical and Physical Academy of Sciences, pp. 1-45

Bi, P., Parton, K. \& Tong, S. (2005). El Nino-Southern Oscillation and vector-borne diseases in Anhui, China. Vector Borne and Zoonotic Diseases, Vol. 5, No. 2, (Summer 2005), pp. 95-100, ISSN 1530-3667

Bi, P., Tong, S., Donald, K. Parton, K. \& Ni, J. (2003)., Climatic variables and transmission of malaria: a 12-year data analysis in Shuchen County, China. Public Health Reports, Vol. 118, No. 1, (January-February 2003), pp. 65-71, ISSN 0033-3549

Bolker, B.M. \& Grenfell, B.T. (1993). Chaos and biological complexity in measles dynamics. Proceedings of the Royal Society B: Biological Sciences, Vol. 251, No. 1330, (January 1993), pp. 75-81, ISSN 0962-8452

Bomblies, A., Duchemin, J. B. \& Eltahir, E. A. (2009). A mechanistic approach for accurate simulation of village scale malaria transmission. Malaria Journal, Vol. 8, (October 2009), pp. 223, ISSN 1475-2875

Bouma, M. J., Poveda, G., Rojas, W., Chavasse, D., Quinones, M., Cox, J. \& Patz, J. (1997). Predicting high-risk years for malaria in Colombia using parameters of El Nino Southern Oscillation. Tropical Medicine and International Health, Vol. 2, No. 12, (December 1997), pp. 1122-1127, ISSN 1360-2276

Bouma, M. J., Sondorp, H. E. \& van der Kaay, H. J. (1994). Climate change and periodic epidemic malaria. Lancet, Vol. 343, No. 8910, (June 1994), pp. 1440, ISSN 0140-6736

Bradshaw, W. \& Holzapfel, C. (1983). Predator-mediated, non-equilibrium coexistence of tree-hole mosquitos in southeastern North-America. Oecologia, Vol. 57, No. 1-2, pp. 239-256, ISSN 0029-8549

Briët, O. J., Vounatsou, P., Gunawardena, D. M., Galappaththy, G. N. \& Amerasinghe, P. H. (2008). Temporal correlation between malaria and rainfall in Sri Lanka. Malaria Journal, Vol. 7, (May 2008), pp. 77, ISSN 1475-2875

Brownstein, J., Holford, T. \& Fish, D. (2005). Effect of Climate Change on Lyme Disease Risk in North America. Ecohealth, Vol. 2, No. 1, (March 2005), pp. 38-46, ISSN 1612-9202

Campbell-Lendrum, D., Pruss-Ustun, A. \& Corvalan, C. (2003). How much disease could climate change cause, In: Climate change and human health - Risks and Responses, McMichael, A.J., Campbell-Lendrum, D.H., Corvalán, C.F., Ebi, K.L., Githeko, A.K., Scheraga, J.D. \& Woodward, A. (Eds), pp. 133-158, World Health Organisation, ISBN 924156248 X, Geneva.

Casimiro, E., Calheiros, J., Santos, F. D. \& Kovats, S. (2006). National Assessment of Human Health Effects of Climate Change in Portugal: Approach and Key Findings. Environmental Health Perspectives, Vol. 114, No. 12, (December 2006), pp. 1950-1956, ISSN 0091-6765

Chan, N. Y., Ebi, K. L., Smith, F., Wilson, T. F. \& Smith, A. E. (1999). An integrated assessment framework for climate change and infectious diseases. Environmental Health Perspectives, Vol. 107, No. 5 (May 1999), pp. 329-337, ISSN 0091-6765 
Charlwood, J. D., Smith, T., Kihonda, J., Heiz, B., Billingsley, P. F. \& Takken, W. (1995) Density-Independent Feeding Success of Malaria Vectors (Diptera, Culicidae) in Tanzania. Bulletin of Entomological Research, Vol. 85, No. 1, pp. 29-35, ISSN 0007-4853

Coluzzi, M., Sabatini, A., Petrarca, V. \& Di Deco, M.A. (1979). Chromosomal differentiation and adaptation to human environments in the Anopheles gambiae complex. Transactions of the Royal Society of Tropical Medicine and Hygiene, Vol. 73, No. 5, pp. 483-497, ISSN 0035-9203

Cook, G. C. (1992). Effect of global warming on the distribution of parasitic and other infectious diseases: a review. Journal of the Royal Society of Medicine, Vol. 85, No. 11, (November 1992), pp. 688-91, ISSN: 0141-0768

Craig, M. H., Snow, R. W. \& le Sueur, D. (1999). A climate-based distribution model of malaria transmission in sub-Saharan Africa. Parasitology Today, Vol. 15, No. 3, (March 1999), pp. 105-111, ISSN 0169-4758

Cross, E.R. \& Hyams, K.C. (1996). The potential effect of global warming on the geographic and seasonal distribution of Phlebotomus papatasi in southwest Asia. Environmental Health Perspectives,Vol.104(7), (Jul 1996), pp.: 724-727, ISSN 0091-6765

Depinay, J. M. O., Mbogo, C. M., Killeen, G., Knols, B., Beier, J., Carlson, J., Dushoff, J., Billingsley, P., Mwambi, H., Githure, J., Toure, A. M. \& Ellis McKenzie, F. (2004). A simulation model of African Anopheles ecology and population dynamics for the analysis of malaria transmission. Malaria Journal, Vol. 3, (July 2004), pp. 29, ISSN $1475-2875$

Dye, C. (1984). Models for the population dynamics of the yellow fever mosquito, Aedes aegypti . Journal of Animal Ecology, Vol. 53, No. 1, pp. 247-268.

Epstein, P.R. (2001). Climate change and emerging infectious diseases. Microbes and Infection, Vol. 3, No. 9, (July 2001), pp. 747-754, ISSN 1286-4579

Ermert, V., Fink, A., Jones, A. \& Morse, A. (2011a). Development of a new version of the Liverpool Malaria Model. I. Refining the parameter settings and mathematical formulation of basic processes based on a literature review. Malaria Journal, Vol. 10, No. 1, (February 2011), pp. 35, ISSN 1475-2875

Ermert, V., Fink, A., Jones, A. \& Morse, A. (2011b). Development of a new version of the Liverpool Malaria Model. II. Calibration and validation for West Africa. Malaria Journal, Vol. 10, (March 2011), pp.62, ISSN 1475-2875

Ernst, K. C., Adoka, S. O., Kowuor, D. O., Wilson, M. L. \& John, C. C. (2006). Malaria hotspot areas in a highland Kenya site are consistent in epidemic and non-epidemic years and are associated with ecological factors. Malaria Journal, Vol. 5, (September 2006), pp. 78, ISSN 1475-2875

Fillinger, U., Sonye, G.,Killeen, G.F., Knols, B.G. \& Becker, N. (2004). The practical importance of permanent and semipermanent habitats for controlling aquatic stages of Anopheles gambiae sensu lato mosquitoes: operational observations from a rural town in western Kenya. Tropical Medicine and International Health, Vol. 9, No. 12 (December 2004), pp. 1274-1289, ISSN 1360-2276

Gagnon, A., Bush, A. \& Smoyer Tomic, K. (2001). Dengue epidemics and the El Nino Southern Oscillation. Climate Research, Vol. 19, No. 1, (November 2001), pp. 35-43, ISSN 0936-577X

Gambhir., M. \& Michael, E. (2008). Complex ecological dynamics and eradicability of the vector borne macroparasitic disease, lymphatic filariasis. PLoS ONE, Vol. 3, No. 8, (August 2008), pp. e2874, ISSN 1932-6203 
Garg, A., Dhiman, R. C., Bhattacharya, S. \& Shukla, P. R. (2009). Development, malaria and adaptation to climate change: a case study from India. Environmental management, Vol. 43, No. 5, (May 2009), pp. 779-789, ISSN 1432-1009

Gaudart, J., Touré, O., Dessay, N., Dicko, A., Ranque, S., Forest, L., Demongeot, J., Doumbo, O. K. \& Knols, B. G. (2009). Modelling malaria incidence with environmental dependency in a locality of Sudanese savannah area, Mali. Malaria Journal, Vol. 8, (March 2009), pp. 61, ISSN 1475-2875

Githeko, A. K., Lindsay, S. W., Confalonieri, U. E. \& Patz J. A. (2000). Climate change and vector-borne diseases: a regional analysis. Bulletin of the World Health Organisation, Vol. 78, No. 9, (October 2000), pp. 1136-1147, ISSN: 0042-9686

Goklany, I. M. (2004). Climate change and malaria. Science, Vol. 306, No. 5693, (October 1995), pp. 55-57, ISSN 1095-9203

Grassly, N. \& Fraser, C. (2006). Seasonal infectious disease epidemiology. Proceedings of the Royal Society B: Biological Sciences, Vol. 273, No. 1600, (October 2006), pp. 2541-2550, ISSN 0962-8452

Gray, J.S., Dautel, H., Estrada-Pea, A., Kahl, O. \& Lindgren, E. (2009). Effects of climate change on ticks and tick-borne diseases in Europe. Interdisciplinary Perspectives on Infectious Diseases, Vol. 2009, (January 2009), pp. 593232, ISSN 1687-708X

Gubler, D. J., Reiter, P., Ebi, K. L., Yap, W., Nasci, R. \& Patz, J. A. (2001). Climate variability and change in the United States: potential impacts on vector- and rodent-borne diseases. Environmental Health Perspectives, Vol. 109, No. Suppl 2, (May 2001), pp. 223-233, ISSN 0091-6765

Hales, S. \& Woodward, A. (2005). Global climate change and malaria. Lancet Infectious Diseases, Vol. 5, No. 5 (May 2005), pp. 258-259, ISSN 1473-3099

Hales, S., de Wet, N., Maindonald, J. \& Woodward, A. (2002). Potential effect of population and climate changes on global distribution of dengue fever: an empirical model. Lancet, Vol. 360, No. 9336, (September 2002), pp. 830-834, ISSN 0140-6736

Hales, S., Weinstein, P., Souares, Y. \& Woodward, A. (1999). El Niño and the dynamics of vectorborne disease transmission. Environmental Health Perspectives, Vol. 107, No. 2, (February 1999), pp. 99-102, ISSN 0091-6765

Hall, G., D'Souza, R. \& Kirk, M. (2002). Foodborne disease in the new millennium: out of the frying pan and into the fire? Medical Journal of Australia, Vol. 177, No. 11-12, (December 2002), pp.614-618, ISSN 0025-729X

Hassell, M.P. (1987). Detecting regulation in patchily distributed animal populations. Journal of Animal Ecology, Vol. 56, pp. 705-713

Hay, S. I., Cox, J., Rogers, D. J., Randolph, S. E., Stern, D. I., Shanks, G. D., Myers, M. F. \& Snow, R. W. (2002). Climate change and the resurgence of malaria in the East African highlands. Nature, Vol. 415, No. 6874, (February 2002), pp. 905-909, ISSN 0028-0836

Hay, S. I., Rogers, D. J., Randolph, S. E., Stern, D. I., Cox, J., Shanks, G. D. \& Snow, R. W. (2002). Hot topic or hot air? Climate change and malaria resurgence in East African highlands. Trends in Parasitology, Vol. 18, No. 12, (December 2002), pp. 530-534, ISSN 1471-4922

Hay, S. I., Shanks, G. D., Stern, D. I., Snow, R. W., Randolph, S. E. \& Rogers, D. J. (2005). Climate variability and malaria epidemics in the highlands of East Africa. Trends in Parasitology, Vol. 21, No. 2, (February 2005), pp. 52-53, ISSN $1471-4922$

Hay, S., Guerra, C., Gething, P., Patil, A., Tatem, A., Noor, A., Kabaria, C., Manh, B., Elyazar, I.R.F., Brooker, S., Smith, D., Moyeed, R. \& Snow, R. (2009). A world malaria map: 
Plasmodium falciparum endemicity in 2007. PLoS Medicine, Vol. 6, No. 3, (October 2009), pp. e1000048, ISSN 1549-1277

Hay,S I., Myers, M.F., Burke, D.S., Vaughn, D.W., Endy, T., Ananda, N., Shanks, G.D., Snow, R.W. \& Rogers, D.J. (2000). Etiology of interepidemic periods of mosquitoborne disease. Proceedings of the National Academy of Sciences of the United States of America, Vol. 97, No. 16, (August 2000), pp. 9335-9339, ISSN 0027-8424

Herrera-Martinez, A.D. \& Rodríguez-Morales, A.J. (2010). Potential influence of climate variability on dengue incidence registered in a western pediatric hospital of Venezuela. Tropical Biomedicine, Vol. 27, No. 2, (August 2010), pp. 280-286

Hochedez, P. Jaureguiberry, S., Debruyne, M., Bossi, P., Hausfater, P., Brucker, G., Bricaire, F. \& Caumes, E. (2006). Chikungunya infection in travelers. Emerging Infectious Diseases, Vol. 12, No. 10, (October 2006), pp. 1565-1567, ISSN 1080-6040

Hopp, M. \& Foley, J. (2003). Worldwide fluctuations in dengue fever cases related to climate variability. Climate Research, Vol. 25, No. 1, (Oct 2003), pp. 85-94, ISSN 0936-577X

Hoshen M. B. \& Morse, A. P. (2005). A model structure for estimating malaria risk, In: Environmental Change and Malaria Risk: Global and Local Implications, Takken, W., Martens, P. \& Bogers, R.J. (Eds.), pp. 41-50, Springer, ISBN 978-1-4020-4541-7

Hoshen, M. B. \& Morse, A. P. (2004). A weather-driven model of malaria transmission. Malaria Journal, Vol. 3, (September 2004), pp. 32, ISSN 1475-2875

Huang, J., Walker, E. D., Vulule, J. \& Miller, J. R. (2006). Daily temperature profiles in and around Western Kenyan larval habitats of Anopheles gambiae as related to egg mortality, Malaria Journal, Vol. 5, (October 2006), pp. 87, ISSN 1475-2875

Hunter, P. R. (2003). Climate change and waterborne and vector-borne disease. Journal of Applied Microbiology, Vol. 94 Suppl, (April 2003), pp. 37S-46S, ISSN: 1364-5072

Inglis, T.J.J. \& Sousa, A. (2009). The public health implications of melioidosis. Brazilian Journal of Infectious Diseases, Vol. 13, No. 1, (Feb 2009), pp. 59-66, ISSN 1413-8670

IPCC (Intergovernmental Panel on Climate Change). (2007). Climate Change 2007 : Synthesis Report. Contribution of Working Groups I, II and III to the Fourth Assessment Report of the Intergovernmental Panel on Climate Change. IPCC, ISBN 6130093179, Geneva

Isaäcson, M. (1989). Airport malaria: a review. Bulletin of the World Health Organisation, Vol. 67, No. 6, pp. 737-743, ISSN 0042-9686

Janssen, M. A. \& Martens, W. J. (1997). Modeling malaria as a complex adaptive system. Artificial Life, Vol. 3, No. 3, (Summer 1997), pp. 213-236, ISSN 1064-5462

Jawara, M., Pinder, M., Drakeley, C., Nwakanma, D., Jallow, E., Bogh, C., Lindsay, S. \& Conway, D. (2008). Dry season ecology of Anopheles gambiae complex mosquitoes in The Gambia. Malaria Journal, Vol. 7, (August 2008), pp. 156, ISSN 1475-2875

Juliano, S. A. (2007). Population Dynamics. Journal of the American Mosquito Control Association, Vol. 23, No. 2 Suppl, pp. 265-275, ISSN 8756-971X

Kedmi, M., Herziger, Y., Galon, N., Cohen, R., Perel, M., Batten, C., Braverman, Y., Gottlieb, Y., Shpigel, N. \& Klement, E. (2010). The association of winds with the spread of EHDV in dairy cattle in Israel during an outbreak in 2006. Preventive Veterinary Medicine. Vol. 96, No. 3-4, (September 2010), pp. 152-160, ISSN 0167-5877

Keeling, M.J. (1999a). Spatial models of interacting populations, In: Advanced Ecological Theory: principles and applications, McGlade, J.M. (Ed.), pp. 64-99, Blackwell Science, ISBN 0865427348, Oxford

Khasnis, A. A. and Nettleman, M. D. (2005). Global warming and infectious disease. Archives of Medical Research, Vol. 36, No. 6, (Nov-Dec 2005), pp. 689-696, ISSN 0188-4409 
Kilian, A H., Langi, P., Talisuna, A. \& Kabagambe, G. (1999). Rainfall pattern, El Nino and malaria in Uganda. Transactions of the Royal Society of Tropical Medicine and Hygiene, Vol. 93, No. 1, (January-February 1999), pp. 22-23, ISSN 0035-9203

Kirby, M. J. \& Lindsay, S. W. (2004). Responses of adult mosquitoes of two sibling species, Anopheles arabiensis and A. gambiae s.s. (Diptera: Culicidae), to high temperatures. Bulletin of Entomolological Research, Vol. 94, No. 5, (October 2004), pp. 441-448, ISSN 0007-4853

Kirby, M. J. \& Lindsay, S. W. (2009). Effect of temperature and inter-specific competition on the development and survival of Anopheles gambiae s. s. and An. arabiensis larvae. Acta Tropica, Vol. 109, No. 2, (Feb 2009), pp. 118-123, ISSN 1873-6254

Knutti, R. (2008). Should we believe model predictions of future climate change? Philosophical Transactions of the Royal Society A: Mathematical, Physical and Engineering Sciences, Vol. 366, No. 1885, pp. 4647-4664, ISSN 1364-503X

Koelle, K., Pascual, M. \& Yunus, M. (2005). Pathogen adaptation to seasonal forcing and climate change. Proceedings of the Royal Society B: Biological Sciences, Volume: 272, No. 1566, (May 2005), pp. 971-977, ISSN 0962-8452

Koenraadt, C.J.M., Githeko, A.K. \& Takken,W. (2004). The effects of rainfall and evapotranspiration on the temporal dynamics of Anopheles gambiae s.s. and Anopheles arabiensis in a Kenyan village. Acta Tropica, Vol. 90, No. 2, pp. 141-153, ISSN 0001-706X

Kovats, R.S., Bouma, M., Hajat S., Worrall, E, \& Haines, A., (2003). El Niño and health. Lancet, Vol. 362, No. 9394, (November 2003), pp. 1481-1489, ISSN 0140-6736

Kristan, M., Abeku, T., Beard, J., Okia, M., Rapuoda, B. ,Sang, J. \& Cox, J. (2008). Variations in entomological indices in relation to weather patterns and malaria incidence in East African highlands: implications for epidemic prevention and control. Malaria Journal, Vol. 7, (November 2008), pp. 231, ISSN 1475-2875

Lane, R.P. \& Crosskey, R.W. (Eds.). (1993). Medical insects and arachnids, Chapman \& Hall, IBSN 0412400006, London

Lindblade, K A., Walker, E.D., Onapa, A.W., Katungu, J. \& Wilson, M L. (1999). Highland malaria in Uganda: prospective analysis of an epidemic associated with El Niño. Transactions of the Royal Society of Tropical Medicine and Hygiene, Vol. 93, No. 5, (September-October 1999), pp. 480-487, ISSN 0035-9203

Lindblade, K. A., Walker, E. D., Onapa, A. W., Katungu, J. \& Wilson, M. L. (2000). Land use change alters malaria transmission parameters by modifying temperature in a highland area of Uganda. Tropical Medicine and International Health, Vol. 5, No. 4 (May 2000), pp. 263-274, ISSN 1360-2276

Lindsay, S. W. \& Birley, M. H. (1996). Climate change and malaria transmission. Annals of Tropical Medicine and Parasitology, Vol. 90. No. 6, (December 1996), pp. 573-588, ISSN 0003-4983

Lindsay, S. W. \& Martens, W. J. (1998). Malaria in the African highlands: past, present and future. Bulletin of the World Health Organisation, Vol. 76(1), pp. 33-45, ISSN 0042-9686

Linthicum, K.J., Anyamba, A. Tucker, C.J., Kelley, P.W., Myers, M.F. \& Peters, C.J. (1999). Climate and satellite indicators to forecast Rift Valley fever epidemics in Kenya. Science, Vol. 285, No. 5426, (July 1999), pp. 397-400, ISSN 0036-8075

Lipp, E. Huq, A. \& Colwell, R. (2002). Effects of global climate on infectious disease: the cholera model. Clinical Microbiology Reviews, Vol. 15, No. 4, (October, 2002), pp. 757770, ISSN 0893-8512

López-Vélez, R. \& Molina Moreno, R. (2005). Cambio climático en España y riesgo de enfermedades infecciosas y parasitarias transmitidas por artrópodos y roedores. 
Revista Española de Salud Pública, Vol. 79, No. 2, (March-April 2005), pp. 177-190, ISSN 1135-5727

Lundkvist, E., Landin, J., Jackson, M. \& Svensson, C. (2003). Diving beetles (Dytiscidae) as predators of mosquito larvae (Culicidae) in field experiments and in laboratory tests of prey preference. Bulletin of Entomological Research, Vol. 93, No. 3, (June 2003), pp. 219-226, ISSN 0007-4853

Mabaso, M. L., Vounatsou, P., Midzi, S., Da Silva, J. \& Smith, T. (2006). Spatio-temporal analysis of the role of climate in inter-annual variation of malaria incidence in Zimbabwe. International Journal of Health Geographics, Vol. 5, (May 2006), pp. 20, ISSN 1476-072X

Mantilla, G., Oliveros, H. \& Barnston, A. G. (2009). The role of ENSO in understanding changes in Colombia's annual malaria burden by region, 1960-2006. Malaria Journal, Vol. 8, (January 2009), pp. 6, ISSN 1475-2875

Martens, P. (1998). Health and Climate Change: Modelling the Impacts of Global Warming and Ozone Depletion. Easrthscan, ISBN 1853835226

Martens, P. \& Hall, L. (2000). Malaria on the move: human population movement and malaria transmission. Emerging Infectious Diseases, Vol. 6, No. 2, (March-April 2000), pp. 103-109, ISSN 1080-6040

Martens, W. J., Niessen, L. W., Rotmans, J., Jetten, T. H. \& McMichael, A. J. (1995). Potential impact of global climate change on malaria risk. Environmental Health Perspectives, Vol. 103, No. 5, (May 1995), pp. 458-64, ISSN 0091-6765

Mas Coma, S., Valero, M. \& Bargues, M. (2009). Climate change effects on trematodiases, with emphasis on zoonotic fascioliasis and schistosomiasis. Veterinary Parasitology, Vol. 163, No. 4, (August 2009), pp.264-280, ISSN 0304-4017

Mattingly, P.F. (1977). Names for the Anopheles gambiae complex. Mosquito Systematics, Vol. 9, No. 3, pp. 323-328

McMichael, A., Woodruff, R. \& Hales, S. (2006). Climate change and human health: present and future risks. Lancet, Vol. 367, No. 9513, (Sept 2006), pp. 859-69, ISBN 0140-6736

Metz, J.A.J \& Diekmann, O. (1986). The dynamics of physiologically structured populations, Springer-Verlag, ISBN 0387167862, Berlin

Michael, E. (2010). Trypanosomes, leishmania and filarial infections, In: Environmental Medicine, Ayres, J.G., Harrison, R.M., Nichols G.L. \& Maynard, R.L. (Eds), pp. 424433, Hodder Arnold, ISBN 9780340946565, London

Moffett, A., Shackelford, N. \& Sarkar S. (2007). Malaria in Africa: Vector Species' Niche Models and Relative Risk Maps. PLoS ONE, Vol. 2 (9), (Sept 2007), ISSN 1932-6203

Mogi,M.; Miyagi,I.; Cabrera,B.D. (1984) Development and survival of immature mosquitoes (Diptera: Culicidae) in Philippine rice fields. Journal of Medical Entomology, Vol. 21, No. 3, (May 1984), pp. 283-291, ISSN 0022-2585; 0022-2585

Molineaux, L., Storey, J, Cohen, J \& Thomas, A. (1980). A longitudinal study of human malaria in the West African Savanna in the absence of control measures: relationships between different Plasmodium species, in particular P. falciparum and P. malariae. American Journal of Tropical Medicine and Hygiene, Vol. 29, No. 5, (September 1980), pp. 725-737, ISSN 0002-9637

Murphy, J., Sexton, D., Barnett, D., Jones, G., Webb, M. \& Collins, M. (2004). Quantification of modelling uncertainties in a large ensemble of climate change simulations. Nature, Vol. 430, No. 7001, (August 2004), pp. 768-772, ISSN 0028-0836

Ndiaye, P. I., Bicout, D. J., Mondet, B. \& Sabatier, P. (2006). Rainfall triggered dynamics of Aedes mosquito aggressiveness. Journal of Theoretical Biology, Vol. 243, No. 2, (November 2006), pp. 222-229, ISSN 0022-5193 
Paaijmans, K. P., Wandago, M. O., Githeko, A. K. \& Takken, W. (2007). Unexpected High Losses of Anopheles gambiae Larvae Due to Rainfall. PLoS ONE, Vol. 2, No. 11, (November 2007), ISSN 1932-6203

Paaijmans, K. P., Huijben, S., Githeko, A. K. \& Takken, W. (2009). Competitive interactions between larvae of the malaria mosquitoes Anopheles arabiensis and Anopheles gambiae under semi-field conditions in western Kenya. Acta Tropica, Vol. 109, No. 2, (February 2009), pp. 124-130, ISSN 1873-6254

Paaijmans, K., Blanford, S., Bell, A., Blanford, J., Read, A. \& Thomas, M. (2010). Influence of climate on malaria transmission depends on daily temperature variation. Proceedings of the National Academy of Sciences of the United States of America, Vol. 107, No. 107, (August 2010), pp. 15135-15139, ISSN 0027-8424

Palmer, T., Doblas Reyes, F., Hagedorn, R. \& Weisheimer, A. (2005). Probabilistic prediction of climate using multi-model ensembles: from basics to applications. Philosophical Transactions of the Royal Society B: Biological Sciences, Vol. 360, No. 1463, (November 2005), pp. 1991-1998, ISSN 0962-8436

Pampana, E. J. (1969). A textbook of malaria eradication (2nd edition), Oxford University Press, ISBN 019264212X, London

Parham, P.E. \& Michael, E. (2010). Modeling the Effects of Weather and Climate Change on Malaria Transmission. Environmental Health Perspectives, Vol. 118, No. 5, (May 2010), pp. 620-626, ISSN 0091-6765

Parham, P.E., \& Michael, E. (2011). Outbreak properties of epidemic models : The roles of temporal forcing and stochasticity on pathogen invasion dynamics. Journal of Theoretical Biology, Vol. 271, No. 1, (February 2011), pp. 1-9, ISSN $0022-5193$

Parmenter, R.R., Yadav, E.P., Parmenter, C.A., Ettestad, P. \& Gage, K.L. (1999). Incidence of plague associated with increased winter-spring precipitation in New Mexico. American Journal of Tropical Medicine and Hygiene, Vol. 61, No. 5, (November 1999), pp. 814-821, ISSN 0002-9637

Pascual, M., Ahumada, J. A., Chaves, L. F., Rodo, X. \& Bouma, M. (2006). Malaria resurgence in the East African highlands: temperature trends revisited. Proceedings of the National Academy of Sciences of the United States of America, Vol. 103, No. 15, (April 2006), pp. 5829-5834, ISSN 0027-8424

Pascual, M., Bouma, M. \& Dobson, A. (2002). Cholera and climate: revisiting the quantitative evidence. Microbes and Infection, Vol. 4 (2), (Feb 2002), pp.237-245, ISSN 1286-4579

Pascual, M., Cazelles, B., Bouma, M. J., Chaves, L. F. \& Koelle, K. (2008). Shifting patterns: malaria dynamics and rainfall variability in an African highland. Proceedings of the Royal Society B, Vol. 275, No. 1631 (Jan 2008), pp. 123-132, ISSN 0962-8452

Pascual, M., Rod, X., Ellner, S.P., Colwell, R. \& Bouma, M.J. (2000). Cholera dynamics and El Niño-Southern Oscillation. Science, Vol. 289, No. 5485, (September 2000), pp. 17661769, ISSN 0036-8075

Purse, B., Mellor, P., Rogers, D., Samuel, A., Mertens, P.P.C. \& Baylis, M. (2005). Climate change and the recent emergence of bluetongue in Europe. Nature Reviews Microbiology, Vol. 3, No. 2, (February 2005), pp. 171-181, ISSN 1740-1526

Randolph, S E. \& Rogers, D J. (2000). Fragile transmission cycles of tick-borne encephalitis virus may be disrupted by predicted climate change. Proceedings of the Royal Society B - Biological Sciences, Vol. 267, No. 1454, (Sept 2000), pp. 1741-1744, ISSN 0962-8452

Randolph, S E. (1998). Ticks are not Insects: Consequences of Contrasting Vector Biology for Transmission Potential. Parasitology Today, Vol. 14, No. 5, (May 1998), pp.186-192, ISSN 0169-4758 
Randolph, S. (2004). Evidence that climate change has caused 'emergence' of tick-borne diseases in Europe? International Journal of Medical Microbiology, Vol. 293, No. Suppl 37, (April 2004), pp. 5-15, ISSN 1438-4221

Reiter, P. (2001). Climate change and mosquito-borne disease. Environmental Health Perspectives, Vol. 109, No. Suppl 1, (March 2001), pp. 141-161, ISSN 0091-6765

Reiter, P. (2008). Global warming and malaria: knowing the horse before hitching the cart. Malaria Journal, Vol. 7, No. Suppl 1, (December 2008), pp. S3, ISSN 1475-2875

Rogers, D.J. \& Randolph, S.E. (2000). The global spread of malaria in a future, warmer world. Science, Vol. 289, No. 5485, (September 2000), pp. 1763-6, ISSN 0036-8075

Ruiz, D., Poveda, G., Vélez, I. D., Quiñones, M. L., Rúa, G. L., Velásquez, L. E. \& Zuluaga, J. S. (2006). Modelling entomological-climatic interactions of Plasmodium falciparum malaria transmission in two Colombian endemic-regions: contributions to a National Malaria Early Warning System. Malaria Journal, Vol. 5, (August 2006), pp. 66, ISSN 1475-2875

Schaeffer, B., Mondet, B. \& Touzeau, S. (2008). Using a climate-dependent model to predict mosquito abundance: application to Aedes (Stegomyia) africanus and Aedes (Diceromyia) furcifer (Diptera: Culicidae). Infectious Genetics and Evolution, Vol. 8, No. 4, (July 2008), pp. 422-432, ISSN 1567-1348

Scheffer, M., Carpenter, S., Foley, J.A., Folke, C. \& Walker, B. (2001). Catastrophic shifts in ecosystems. Nature, Vol. 413, No. 6856, (October 2001), pp. 591-596 ISSN 0028-0836

Sellers, R.F. \& Pedgley, D.E. (1985). Possible windborne spread to western Turkey of bluetongue virus in 1977 and of Akabane virus in 1979. Journal of Hygiene, Vol. 95, No. 1, (August 1985), pp. 149-158, ISSN 0022-1724

Semenza, J. \& Menne, B. (2009). Climate change and infectious diseases in Europe. Lancet Infectious Diseases, Vol. 9, No. 6, (June 2009), pp. 365-375, ISSN 1473-3099

Service, M.W. (1993). Mosquito ecology: field sampling methods (2nd edition), Elsevier Applied Science, ISBN 1851667989, London

Service, M.W. (1977). Mortalities of the immature stages of species B of the Anopheles gambiae complex in Kenya: comparison between rice fields and temporary pools, identification of predators, and effects of insecticidal spraying. Journal of Medical Entomology, Vol. 13, No. 4-5, (January 1977), pp 535-545, ISSN 0022-2585

Shaman, J., Stieglitz, M., Stark, C., Le Blancq, S. \& Cane, M. (2002). Using a Dynamic Hydrology Model To Predict Mosquito Abundances in Flood and Swamp Water. Emerging Infectious Diseases, Vol. 8, No. 1, (January 2002), pp. 8-13, ISSN 1080-6040

Slingo, J., Bates, K., Nikiforakis, N., Piggott, M., Roberts, M. \&Shaffrey, L. (2009). Developing the next-generation climate system models: challenges and achievements. Philosophical Transactions of the Royal Society A: Mathematical, Physical and Engineering Sciences, Vol. 367, No. 1890, pp. 815-831, ISSN 1364-503X

Solow, A.R. \& Steele, J.H. (1990). On sample size, statistical power and the detection of density-dependence. Journal of Animal Ecology, Vol. 59, pp. 1073-1076

Summers, B.A. (2009). Climate change and animal disease. Veterinary Pathology Online, Vol. 46, No. 6, (July 2009), pp.1185-1186.

Sunahara, T. \& Mogi, M. (2002). Priority effects of bamboo-stump mosquito larae: influences of water exchange and leaf litter input. Ecological Entomology, Vol. 27, No. 3, (June 2002), pp. 346-354, ISSN 0307-6946

Süss, J., Klaus, C., Gerstengarbe, F-W. \& Werner, P. (2008). What makes ticks tick? Climate change, ticks, and tick-borne diseases. Journal of Travel Medicine, Vol. 15, No. 1, (January-February 2008), pp. 39-45, ISSN 1195-1982 
Sutherst, R. W. (2004). Global Change and Human Vulnerability to Vector-Borne Diseases. Clinical Microbiology Reviews, Vol. 17, No. 1, (Jan 2004), pp. 136-73, ISSN 0893-8512

Tebaldi, C. \& Knutti, R. (2007). The use of the multi-model ensemble in probabilistic climate projections. Philosophical Transactions of the Royal Society A: Mathematical, Physical \& Engineering Sciences, Vol. 365, No. 1857, (Aug 2007), pp. 2053-2075, ISSN 1364-503X

Thomson, M., Mason, S., Phindela, T. \& Connor, S. (2005). Use of rainfall and sea surface temperature monitoring for malaria early warning in Botswana. American Journal of Tropical Medicine and Hygiene, Vol. 73, No. 1, (July 2005), pp.214-221, ISSN 0002-9637

Thomson, M.C. Doblas Reyes, F.J., Mason, S.J. Hagedorn, R., Connor, S.J., Phindela, T., Morse, A.P. \& Palmer, T.N. (2006). Malaria early warnings based on seasonal climate forecasts from multi-model ensembles. Nature, Vol. 439, No. 7076, (February 2006), pp. 576-579, ISSN 0028-0836

Tol, R.S.J. \& Dowlatabadi, H. (2001). Vector-borne diseases, development \& climate change. Integrated Assessment, Vol. 2, No.4, pp. 173-181

Warrell, D.A. \& Gilles, H.M. (2002). Essential Malariology (4th edition), Arnold, ISBN 0340740647, London

Watts, D., Burke, D., Harrison, B., Whitmire, R. \& Nisalak, A. (1987). Effect of temperature on the vector efficiency of Aedes-aegypti for dengue-2 virus. American Journal of Tropical Medicine and Hygiene, Vol. 36 (1), (Jan 1987), pp. 143-152, ISSN 0002-9637

Whitehorn, J., Farrar, J. (2010). Dengue. British Medical Bulletin, Vol. 95, No. 1, (July 2010), pp. 161-Start Page: 161-173, ISSN 0007-1420

WHO (World Health Organisation). (1999). Early human health effects of climate change. Report on a WHO workshop. WHO, Retrieved from http://www.euro.who.int/ _data/assets/pdf_file/0006/119184/E64599.pdf

WHO (World Health Organisation). (2008). World Malaria Report 2008. WHO, Retrieved from http://www.who.int/malaria/publications/atoz/9789241563697/en/

Willett, K., Jones, P., Gillett, N. \& Thorne, P. (2008). Recent changes in surface humidity: development of the HadCRUH dataset. Journal of Climate, Vol. 21, No. 20, pp. 53645383, ISSN 0894-8755

Willett, K., Gillett, N., Jones, P. \& Thorne, P. (2007). Attribution of observed surface humidity changes to human influence. Nature, Vol. 449, No. 7163, (October 2007), pp.710-712, ISSN 0028-0836

Yang, G., Vounatsou, P., Zhou, X., Tanner, M. \& Utzinger, J. (2005). A potential impact of climate change and water resource development on the transmission of Schistosoma japonicum in China. Parassitologia, Vol. 47, No. 1, (March 2005), pp.127-134, ISSN 0048-2951

Zhou, G., Minakawa N., Githeko A. K., \& Yan G. (2004). Association between climate variability and malaria epidemics in the East African highlands. Proceedings of the National Academy of Sciences of the United States of America, Vol. 101, No. 8, (February 2004), pp. 2375-2380, ISSN 0027-8424 


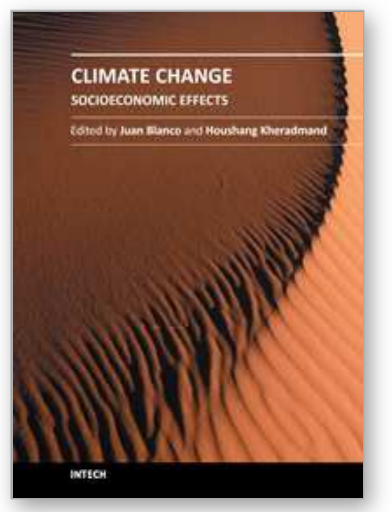

\author{
Climate Change - Socioeconomic Effects \\ Edited by Dr Houshan Kheradmand
}

ISBN 978-953-307-411-5

Hard cover, 454 pages

Publisher InTech

Published online 09, September, 2011

Published in print edition September, 2011

This book shows some of the socio-economic impacts of climate change according to different estimates of the current or estimated global warming. A series of scientific and experimental research projects explore the impacts of climate change and browse the techniques to evaluate the related impacts. These 23 chapters provide a good overview of the different changes impacts that already have been detected in several regions of the world. They are part of an introduction to the researches being done around the globe in connection with this topic. However, climate change is not just an academic issue important only to scientists and environmentalists; it also has direct implications on various ecosystems and technologies.

\title{
How to reference
}

In order to correctly reference this scholarly work, feel free to copy and paste the following:

Paul E. Parham, Céline Christiansen-Jucht, Diane Pople and Edwin Michael (2011). Understanding and Modelling the Impact of Climate Change on Infectious Diseases - Progress and Future Challenges, Climate Change - Socioeconomic Effects, Dr Houshan Kheradmand (Ed.), ISBN: 978-953-307-411-5, InTech, Available from: http://www.intechopen.com/books/climate-change-socioeconomic-effects/understanding-and-modellingthe-impact-of-climate-change-on-infectious-diseases-progress-and-future-

\section{INTECH}

open science | open minds

\section{InTech Europe}

University Campus STeP Ri

Slavka Krautzeka 83/A

51000 Rijeka, Croatia

Phone: +385 (51) 770447

Fax: +385 (51) 686166

www.intechopen.com

\section{InTech China}

Unit 405, Office Block, Hotel Equatorial Shanghai

No.65, Yan An Road (West), Shanghai, 200040, China

中国上海市延安西路65号上海国际贵都大饭店办公楼405单元

Phone: +86-21-62489820

Fax: $+86-21-62489821$ 
(C) 2011 The Author(s). Licensee IntechOpen. This chapter is distributed under the terms of the Creative Commons Attribution-NonCommercialShareAlike-3.0 License, which permits use, distribution and reproduction for non-commercial purposes, provided the original is properly cited and derivative works building on this content are distributed under the same license. 